\title{
DETERMINATION OF POLYCYCLIC AROMATIC HYDROCARBONS (PAHs) IN OIL SHALE PROCESSING WASTES: CURRENT PRACTICE AND NEW TRENDS
}

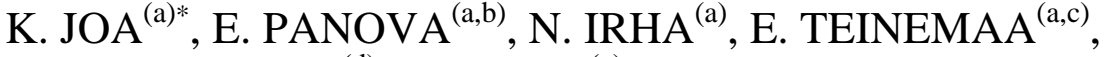 \\ J. LINTELMANN ${ }^{(d)}$, U. KIRSO $^{(a)}$ \\ (a) National Institute of Chemical Physics and Biophysics, Akadeemia tee 23, 12618 \\ Tallinn, Estonia \\ (b) Tartu University, Institute of Chemistry, Jakobi 2, 51014 Tartu, Estonia \\ (c) Estonian Environmental Research Center, Marja 4D, 10617 Tallinn, Estonia \\ (d) Helmholtz Zentrum München, German Research Center for Environmental \\ Health, Institute of Ecological Chemistry, Ingolstädter Landstrasse 1, D-85764 \\ Neuherberg, Germany
}

\begin{abstract}
In the present study a critical evaluation of analytical methods for the determination of PAHs in wastes originating from fossil fuel processing in general, and particularly from combustion and retorting of Estonian oil shale is presented. The analysis for PAHs in solid matrices includes several procedures, i.e. separation, cleanup and final determination. Classical and modern separation methods are characterized and examples of their use for oil shale wastes are demonstrated. For the final determination of PAHs in oil shale matrices chromatographic methods are used. A new approach involving the use of fluorinated PAHs as internal standards is introduced and discussed.
\end{abstract}

\section{Introduction}

Polycyclic aromatic hydrocarbons (PAHs) are ubiquitous environmental contaminants derived from the incomplete combustion of organic materials, e.g. any kind of fossil fuels including oil shale. Due to carcinogenic and mutagenic activity of many representatives of this group of compounds (Table 1), PAH pollution has become a serious environmental problem. That is why the concentration of PAHs in all compartments of the environment, i.e., water, soil and air, is regulated in most countries in the world. Many

\footnotetext{
* Corresponding author: e-mail kelly.joa@kbfi.ee
} 
PAHs are included in the "priority pollutants" listing of the US Environmental Protecting Agency (US EPA) [1] and European Commission (Regulation EC No 166/2006).

Usually, solid wastes contain hazardous trace compounds, including PAHs. PAHs as a specific group of persistent organic pollutants include a wide range of compounds: carbocyclic and heterocyclic, substituted and non-substituted homologues. For simplification of the analysis and regulation proposes it was reasonable to select a set of priority PAHs, to which the criteria were stated. The US EPA [1] proposed for the regulation a set of the most important PAHs, commonly known as the 16 US EPA PAHs (Table 1).

One of the most important properties of PAHs concerning the analytical determination appears to be water solubility. As a rule, PAHs water solubility decreases (and hydrophobic interaction increases) with the increase in the number of fused benzene rings, and with angularity. Thus, high-molecular mass compounds are more slowly desorbed from the matrix and dissolved in an appropriate solvent than low-molecular mass PAHs. Volatilization generally decreases with increasing number of fused rings.

Since chromatographic separations are primarily based on differences in physical properties, the considerable variability described above for PAHs makes sampling, sample preparation, and analysis especially challenging. When several PAHs are studied as a group, a single sample collection, extraction or analysis method may not be adequate. This is further complicated when the more polar derivatives of PAHs are added to the list of analytes [2].

It is well known that the quality of PAHs data generated with respect to accuracy and precision is critical for successful determination of criteria concentrations regulated by law. Controlling the criteria requires a method that produces sufficiently good analysis quality. Quality is important in terms of detection threshold values (lowest measurable concentrations) and precision (random variation in analytical results). An especially complicated task is the quantification of PAHs in different solid materials, because the first step of the procedure includes separation of the PAH fraction from environmental matrices having very different physical-chemical composition and characteristics. Thus, most methodologies for determination of PAHs in complex solid matrices such as soil, sediments or wastes are difficult to perform. It means that the traditional methods of sample preparation are typically time consuming, employing multistep procedures involving a high risk for loss of analytes and the use of extensive amounts of organic solvents. Moreover, the sampling step could give inadequate results due to possible loss of volatile substances during extraction. It is stated that the main source of low quality of analytical data is often the sampling, pretreatment, and separation of analytes and not the final step [4], e.g. quantification of each PAH homologue concerned (Fig. 1). 
Table 1. Selected properties of US EPA 16 priority PAHs [2, 3]

\begin{tabular}{|c|c|c|c|c|c|c|}
\hline PAH & $\begin{array}{l}\text { Abbrevi- } \\
\text { ation }\end{array}$ & Structure & $\begin{array}{c}\text { Molecular } \\
\text { mass, } \\
\text { Daltons }\end{array}$ & $\begin{array}{l}\text { Boiling } \\
\text { point, } \\
{ }^{\circ} \mathrm{C}\end{array}$ & $\begin{array}{c}\text { Vapor } \\
\text { pressure } \\
\text { at } 25^{\circ} \mathrm{C}, \\
\mathrm{Pa}\end{array}$ & $\log K_{o w}$ \\
\hline $\begin{array}{l}\text { Naphthalene } \\
C_{10} H_{8} \\
\text { Acenaphthene } \\
\mathrm{C}_{12} \mathrm{H}_{10}\end{array}$ & $\begin{array}{l}\mathbf{N A} \\
\mathbf{A C}\end{array}$ & & 128 & 278 & $\begin{array}{c}10.4 \\
30 \times 10^{-1}\end{array}$ & $\begin{array}{l}3.37 \\
3.92\end{array}$ \\
\hline $\begin{array}{l}\text { Acenaphthylene } \\
\mathrm{C}_{12} \mathrm{H}_{8}\end{array}$ & $\mathbf{A C N}$ & & 152 & 265 & $9.0 \times 10^{-1}$ & 4.00 \\
\hline $\begin{array}{l}\text { Fluorene } \\
C_{13} H_{10}\end{array}$ & FL & & 166 & 295 & $9.0 \times 10^{-2}$ & 4.18 \\
\hline $\begin{array}{l}\text { Phenanthrene } \\
C_{14} H_{10}\end{array}$ & PHE & & 178 & 339 & $2.0 \times 10^{-2}$ & 4.57 \\
\hline $\begin{array}{l}\text { Anthracene } \\
C_{14} H_{10}\end{array}$ & AN & & 178 & 340 & $1.0 \times 10^{-3}$ & 4.54 \\
\hline $\begin{array}{l}\text { Fluoranthene } \\
\mathrm{C}_{16} \mathrm{H}_{10}\end{array}$ & FA & & 202 & 375 & $1.2 \times 10^{-3}$ & 5.22 \\
\hline $\begin{array}{l}\text { Pyrene } \\
\mathrm{C}_{16} \mathrm{H}_{10}\end{array}$ & PY & & 202 & 360 & $6.0 \times 10^{-4}$ & 5.18 \\
\hline $\begin{array}{l}\text { Benz[a]anthracene } \\
C_{18} H_{12}\end{array}$ & $\mathbf{B}[\mathbf{a}] \mathbf{A}$ & & 228 & 435 & $2.8 \times 10^{-5}$ & 5.91 \\
\hline $\begin{array}{l}\text { Chrysene } \\
C_{18} H_{12}\end{array}$ & CHR & & 228 & 448 & $5.7 \times 10^{-7}$ & 1.65 \\
\hline $\begin{array}{l}\text { Benzo[b]fluo- } \\
\text { ranthene } \\
C_{20} H_{12}\end{array}$ & $\mathbf{B}[\mathbf{b}] \mathbf{F}$ & & 252 & 481 & N/A & 5.80 \\
\hline $\begin{array}{l}\text { Benzo[k]fluo- } \\
\text { ranthene } \\
C_{20} H_{12} \\
\text { Benzo[a]pyrene } \\
C_{20} H_{12}\end{array}$ & $\mathbf{B}[\mathbf{a}] \mathbf{P}$ & & 252 & 495 & $\begin{array}{l}5.2 \times 10^{-8} \\
7.0 \times 10^{-7}\end{array}$ & 6.04 \\
\hline $\begin{array}{l}\text { Benzo[ghi]- } \\
\text { perylene } \\
C_{22} H_{12}\end{array}$ & B[ghi]P & & 276 & N/A & $6 \times 10^{-8}$ & 6.50 \\
\hline $\begin{array}{l}\text { Indeno[1,2,3-cd]- } \\
\text { pyrene } \\
C_{22} H_{12} \\
\text { Dibenz[a,h]- } \\
\text { anthracene } \\
C_{22} H_{14}\end{array}$ & $\mathbf{D}[\mathbf{a h}] \mathbf{A}$ & & 276 & 536 & $3.7 \times 10^{-10}$ & 6.58 \\
\hline
\end{tabular}

$\mathrm{K}_{\mathrm{ow}}-$ octanol/water partition coefficient N/A - not available 


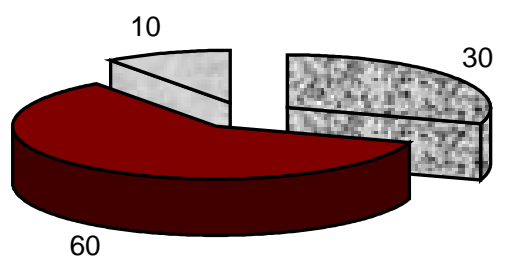

$\square$ sampling and transport
$\square$ pretreatment
$\square$ quantification

Fig. 1. Distribution (per cent) of interferences during analytical determination of hydrophobic organics in solid matrices, based on data by Ramsey et al. [5].

Consequently, the monitoring of PAHs in solid matrices requires optimized sampling and analytical methods that assure reliable concentration measurements. Each pollution source has a unique chemical composition and analytical distribution pattern. It means that the first step of analysis should be the evaluation of sample properties.

A significant pollution source worldwide is processing of fossil fuels. For instance, in Estonia more than $90 \%$ of the energy generation is based on oil shale combustion. Oil production by retorting of oil shale started to be a profitable business during times of restricted resources and high prices of oil products.

A vast literature is available on the chemical analysis of solid wastes from coal combustion, whereas there is a lack of data concerning the oil shale processing residues. This problem is especially important due to the high mineral fraction (60-80\%) of the oil shale itself and the huge amount of solid wastes formed in the processing and disposed to the environment.

The aim of the current study is critical evaluation of methods used by the authors and comparison with relevant literature data concerning the determination of PAHs in different solid matrices originating from fossil fuel processing in general, but mainly from combustion of Estonian oil shale for energy generation and retorting for oil production.

\section{Pretreatment and analysis of solid samples}

A critical overview of separation methods and quantification approaches for PAHs in solid samples with special emphases on oil shale wastes is presented in the following. 
The determination of PAHs in solid matrices such as soils, solid wastes, etc, generally includes several consecutive steps, i.e. separation (extraction), clean-up (fractionation) and final determination (quantification).

\section{Separation and clean-up of PAH fraction}

\section{General}

As a rule, extraction efficiency of PAHs and other organics depends on the following parameters: matrix characteristics $(\mathrm{pH}$, content of water, total organic matter, and unburned carbon [6,7]), solvent composition and volume, extraction temperature and time, and system pressure. A well-known classical method for separation of any group of organic pollutants from solid material is multi-step or Soxhlet extraction [2]. Recently several new methods were introduced, i.e. ultrasound (USE) [7] or microwave-assisted solvent extraction (MAE) $[6,8]$, supercritical fluid extraction (SFE) with $\mathrm{CO}_{2}[9,10]$ or $\mathrm{H}_{2} \mathrm{O}$ [11]. Accelerated solvent extraction (ASE) under high pressure or additionally high temperature $[2,6]$ is also often used. A relatively new method for separation of PAHs is water steam distillation with hexane [12]. Each procedure has its advantages and disadvantages, see Table 2.

For any extraction methods, except SFE, clean-up of the extract is a necessary step in the analysis. Most authors recognise the need for some sample pre-treatment in order to simplify the sample matrix or reduce the amount of solvent when a solvent extraction is required. Widely used at the present time is solid phase extraction [13]. Thin layer chromatography with UV detection is one of the simplest and relatively cheap approaches, which allows separating the fraction of other interfering organics, visualizing the individual compounds [2].

It is important to state that most of extraction methods included in Table 2 could be performed on-line with chromatographic final determination, e.g. gas chromatography coupled with mass-selective detection (GC-MS) or high-performance liquid chromatography (HPLC) [9, 14]. An exception is Soxhlet extraction, which cannot be directly connected to GC. An interfacing trap (solid-phase extraction column, membrane unit) for cleanup is usually needed for ASE, MAE, and USE on-line connection [14].

Solid-phase microextraction (SPME) is a technique whereby an analyte is sorbed onto the surface of a coated silica fiber. This is followed by desorption of the analytes into a suitable instrument such as a GC in most of the applications. In case of SPME-GC, the analytes are thermally desorbed into the injector of the chromatograph [15]. It is, however, generally limited to volatile and thermally stable compounds. SPME seems to be a promising sample-preparation method for PAHs, and may be used for quantitative determination as well as for the assessment of bioavailability of PAHs [15].

Coal ash, shale ash and spent shale are different in terms of PAHs separation due to various mineralogical compositions, content of char and organics, $\mathrm{pH}$ value, etc. The next paragraph describes the use of samples of oil shale combustion ash as target material for analysis. 
Table 2. Characteristics of separation (extraction) methods used for PAHs in solid matrices

\begin{tabular}{|c|c|c|c|}
\hline $\begin{array}{l}\text { Extraction } \\
\text { method }\end{array}$ & Advantages & Disadvantages & References \\
\hline Soxhlet & $\begin{array}{l}\text { Classical and the most } \\
\text { popular method } \\
\text { Overall recovery is good } \\
\text { Smaller solvent and time } \\
\text { consumption if batch (semi- } \\
\text { automatic) system is used }\end{array}$ & $\begin{array}{l}\text { Time consuming } \\
\text { Large solvent consumption, costly } \\
\text { Low selectivity } \\
\text { Relatively small recovery for light } \\
\text { PAHs compared with ASE and } \\
\text { SFE. }\end{array}$ & 16,17 \\
\hline Ultrasonic & Low cost & $\begin{array}{l}\text { Low selectivity } \\
\text { Lower recovery than using } \\
\text { Soxhlet and ASE }\end{array}$ & 2,7 \\
\hline $\begin{array}{l}\text { Microwave } \\
\text { assisted }\end{array}$ & $\begin{array}{l}\text { Small solvent consumption } \\
\text { Low cost } \\
\text { Short extraction time }\end{array}$ & Low selectivity & 2,6 \\
\hline $\begin{array}{l}\text { Accelerated } \\
\text { solvent }\end{array}$ & $\begin{array}{l}\text { Good PAH recovery } \\
\text { Short extraction time } \\
\text { Small solvent consumption } \\
\text { Possible to perform in } \\
\text { adsorbent packed column } \\
\text { without subsequent cleanup }\end{array}$ & Low selectivity & 6 \\
\hline $\begin{array}{l}\text { Supercritical } \\
\text { fluid }\end{array}$ & $\begin{array}{l}\text { Excellent selectivity } \\
\text { Short extraction time }\end{array}$ & $\begin{array}{l}\text { Low recovery of heavy PAHs } \\
\text { Efficiency is matrix-dependent }\end{array}$ & 9,10 \\
\hline $\begin{array}{l}\text { Solid-phase } \\
\text { micro }\end{array}$ & $\begin{array}{l}\text { No solvent needed, } \\
\text { therefore environmentally } \\
\text { friendly. Short extraction } \\
\text { time }\end{array}$ & Low precision & $2,15,18$ \\
\hline
\end{tabular}

Practice on oil shale combustion ash

A test of different extractions on fly ash from exit gas flow duct, after the cyclone and electrostatic precipitators, from the pulverized firing (PF) boiler (Baltic Power Plant, AS Narva Elektrijaamad, Estonia) were performed. USE was carried out with a solvent mixture containing hexane, acetone, and dichloromethane (50/30/20 by volume). The Soxhlet extraction of the ash sample was performed for $6-8 \mathrm{~h}$ with the same mixture. Analytes were separated from the ash by steam distillation into the hexane layer. After the extraction, solvents were evaporated in nitrogen stream and acetonitrile was added before injecting into the HPLC. Clean-up operations on extracts were not performed. Thus, the HPLC chromatograms presented in Fig. 2 characterize the PAHs in a mixture of other organics in combustion ash. It is clearly seen that every extraction method used on oil shale ash has its advantages and disadvantages, depending on physical and chemical characteristics of the pollutants concerned and solvents used.

Soxhlet extraction led to a relatively better recovery of heavier PAHs (chrysene, pyrene and benzofluoranthenes) than ultrasonic extraction, 

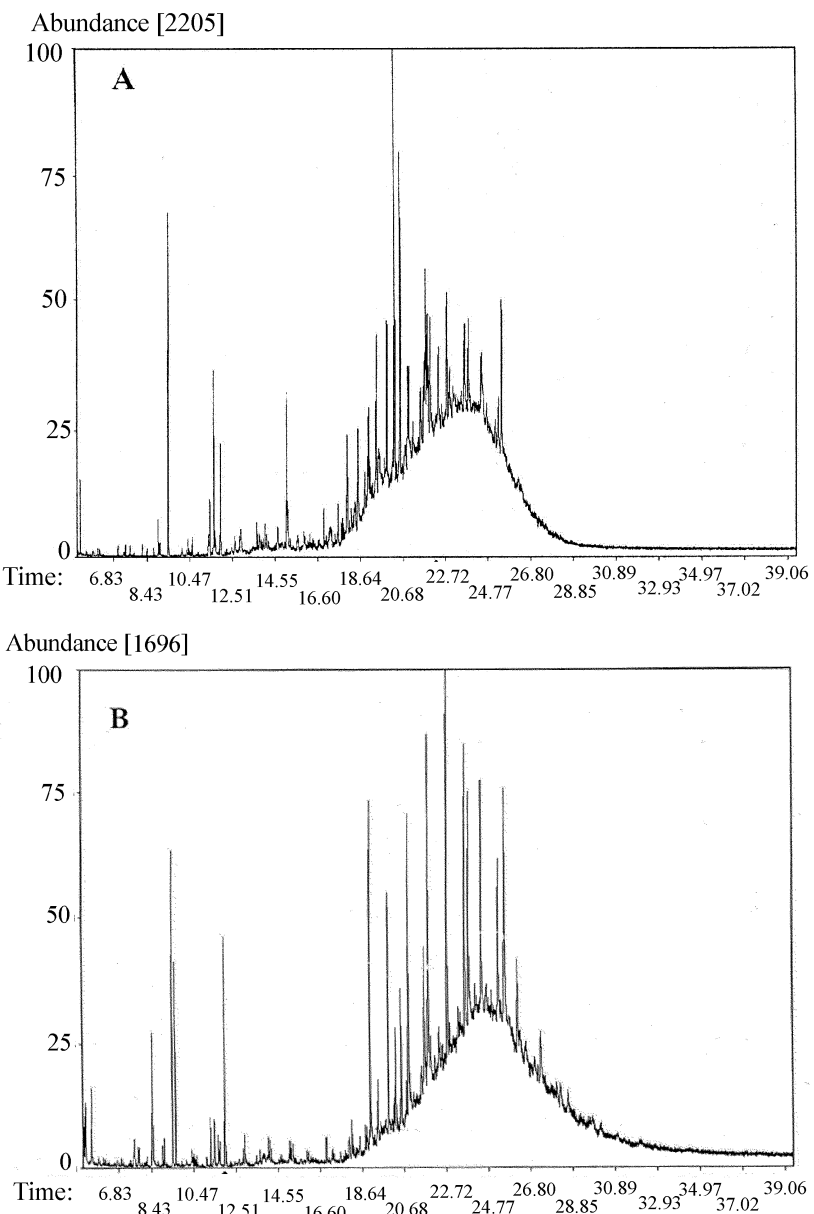

Abundance [73497]

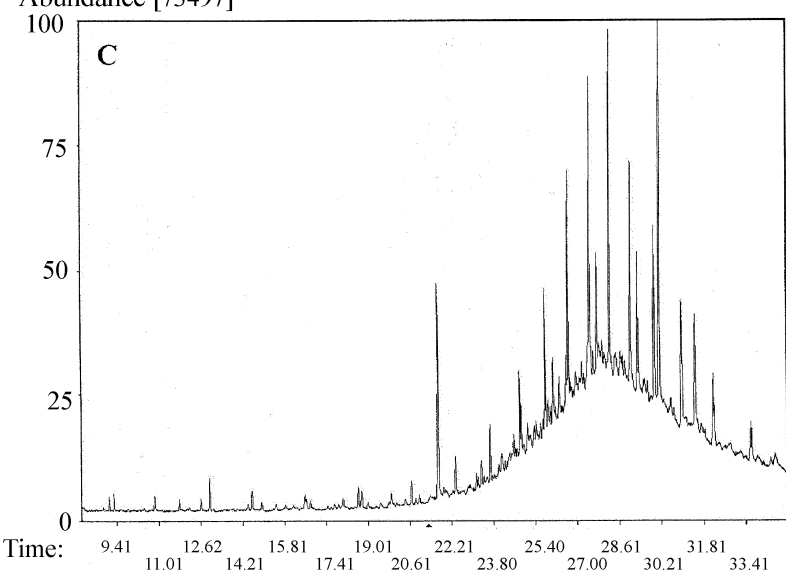

Fig. 2. Total ion chromatograms of PAH compounds extracted from oil shale fly ash samples by different methods: A - steam distillation; B - ultrasonic treatment; C Soxhlet extraction [12]. 
whereas for the lighter PAHs recovery was not so good. Usually, the water steam distillation gave somewhat better results on most PAHs. Good PAH yield by steam distillation is not surprising, because in water steam distillation the boiling point of any compound drops to below $100{ }^{\circ} \mathrm{C}[12]$.

\section{Final determination of PAHs in oil shale matrices}

For quantification of the content of PAHs in ash fractions from combustion or retorting of oil shale various methods and approaches have been used over the years $[12,19,20]$. Quantification of PAHs in oil shale wastes started in the early 1980s in Estonia [19]. Gradually the instrumentation has been significantly improved, and the methods have been more or less standardized. It means that chromatographic determination has been performed with GC or HPLC instrumentation using fluorescence, UV or mass detection. Additionally to in house measurements, the equipment and experience of collaboration partners have been used.

Some results demonstrating the present state of the art of the final determination of PAHs are shown below.

Combustion ash: a characteristic pyrogenic profile of PAHs compounds in combustion ash, resulting from processing of oil shale by PF as well as by circulating fluidized bed (CFB) technology was obtained, i.e. with domination of parent non-alkylated compounds. It is interesting to note that the distribution profile of individual PAH compounds is very close for each ash fractions of both technologies used (see Fig. 3). More than 80 different compounds were identified with GC-MS besides of PAHs in extracts of ash fractions obtained by several separation methods, including combustionrelated higher $n$-alkanes, oxyaromatic compounds, and alkanoic acids [12].

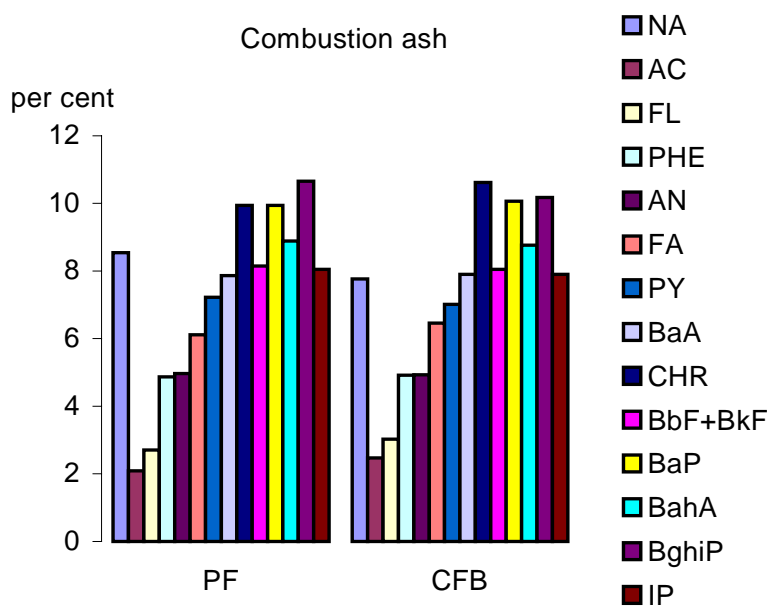

Fig. 3. Distribution (per cent) of individual PAHs compounds in oil shale combustion ash. Pulverized firing (PF) and circulating fluidized-bed (CFB) technology was used for processing; samples were taken from II unit of Electrical Precipitators, Estonian Power Plant (AS Narva Elektrijaamad). Abbreviations see Table 1, BahA Benz[ah]anthracene. 
Spent shale from retorting: Usually the oil shale retorting process results in decomposition of kerogen yielding oil, water, gas, and remaining solid residue. This waste, called spent shale, contains a high amount, i.e. $7-12 \%$ of organic compounds, including toxic phenols and PAHs with total concentration reaching $14 \mathrm{mg} / \mathrm{kg}$ [21]. A huge amount of solid spent shale is deposited in Estonia [21]. Spent shale contains also bitumoids, phenols, $n$ alkanes, branched and cycloalkanes, and non-saturated hydrocarbons [21]. It is interesting to point out that the profile and content of the individual PAH compounds was not changed even after 10 years of storage (Fig. 4). The total content of PAHs in fresh material has been estimated to $13-34 \mathrm{mg} / \mathrm{kg}$, and in aged spent shale $13-29 \mathrm{mg} / \mathrm{kg}$, very close to that of the fresh material [21].

A typical petrogenic PAH profile includes mainly alkylated homologues, and the parent PAHs are least abundant compared the substituted ones. According to some authors [22], alkylated naphthalenes make up approximately $99 \%$ of the total amount, and parent compounds only $1 \%$. For phenanthrenes the corresponding ratio was found to be $88 \%$ and $12 \%$, respectively [22]. Thus, the total content of PAH compounds in spent shale wastes may be significantly higher if substituted derivatives are taken into account.

The recently introduced ultrahigh resolution Fourier transform ion cyclotron mass spectrometry (ICR-FT/MS) was used as a novel method for the characterization of ash fractions and spent shale wastes as examples of complex matrices. A broad set of substituted PAHs and heterocyclic compounds were identified in spent shale wastes using the Europe's first 12 Tesla FRICR mass spectrometer [23].

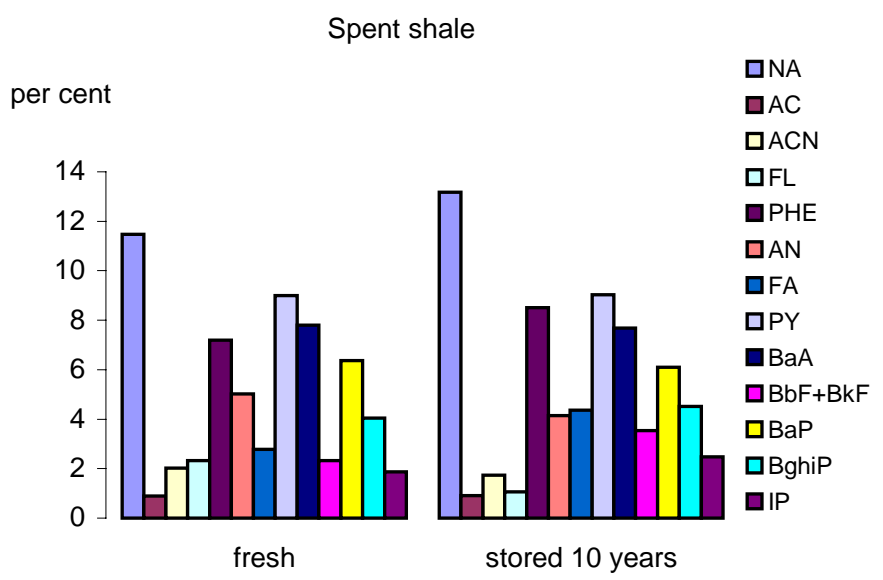

Fig. 4. Distribution (per cent) of individual PAH compounds in spent shale from oil shale retorting, disposed to the environment recently or stored for ten years.

Based on data from VTT, Finland [21]. Abbreviations see Table 1. 


\section{Fluorinated PAHs as a new type of internal standards for chromatographic analysis}

General

It is generally accepted that the accurate determination of micro contaminants in such complex mixtures as wastes requires the use of external, or preferably, internal standards. For PAHs labeled isomers are generally recommended as internal standards. However, some problems arise due to the possibility of scrambling of deuterium and hydrogen atoms. Recently monofluorinated PAHs (F-PAHs $\left.{ }^{\circledR}\right)$ were synthesized. They are considered to be a promising alternative to isotope labeled internal standards because they a) are closely similar to the parent PAHs in terms of chemical and physical properties, b) do not occur in the natural environment and c) are not being produced in appreciable amounts for any industrial, medical or other related purpose [24].

It should be pointed out that those two representatives of F-PAHs, i.e. fluoronaphthalene and 2-fluorobiphenyl, are already recommended as internal standards in the EPA 8100 method for determination of PAHs.

\section{Practice on oil shale ash}

The application of F-PAHs (obtained from Chiron, Trondheim, Norway) as internal standards in GC-MS analysis for PAHs in oil shale wastes, particularly on combustion ash, was performed at the first time for that sort of matrix. Three F-PAH compounds were used as internal standards, i.e. 9fluorobenzo[k]fluoranthene, 1-fluoropyrene and 5-fluoroacenaphthylene. Certified reference materials play an important role in verifying the accuracy and establishing calibration of analytical methods. Therefore, at the start, the suitability of F-PAHs as internal standard was tested on the set of certified 16 priority PAHs, then the water extracts of ash samples were analyzed. Retention time and qualifier ions were determined before the calibration procedure (Table 3 ).

Calibration solutions were prepared with the 16 EPA PAH mix. F-PAHs were used as internal standards. The linear range was established by fivepoint (as a minimum) calibration curves in the range of $0.1-1.0 \mathrm{mg} / \mathrm{ml}$, each calibration level was spiked with internal standards. Use of the internal standards increased the precision of calibration $\left(\mathrm{R}^{2}\right.$ values of calibration curves with only external standards were in the range 0.95-0.96, and more than 0.98 when F-PAHs were used). Using the method described above the following pairs of compounds, e. g., B[b]F and B[k]F; D[a,h]A and IP; AN and PHE, were not successfully resolved and separated. However, the purposes of the analysis can be served by reporting the sum of an unresolved PAH pair. This problem is not new, is described before and can be solved, for instance, by using liquid-crystalline polysiloxane columns [13]. 
Table 3. Retention times and qualifier ions of $\mathbf{1 6}$ priority PAHs and three F-PAHs. Abbreviations see Table 1.

Equipment: GC Agilent HP 7890, Palo Alto, CA, USA, with an HP-5MS capillary column $(30 \mathrm{~m} \times 0.25 \mathrm{~mm} \times 0.25 \mu \mathrm{m})$ and Model 5975B mass selective detector.

Conditions: temperature range from $25{ }^{\circ} \mathrm{C}$ to $320^{\circ} \mathrm{C}$; helium as carrier gas; constant-pressure mode (13.0 psi); splitless mode injection.

Chemstation software Agilent G1701DA GC/MSD was used for the treatment of data.

\begin{tabular}{|c|c|c|c|}
\hline Compound & Retention time & $\begin{array}{l}\text { Target ions, } \\
\mathrm{m} / \mathrm{z}\end{array}$ & $\begin{array}{c}\text { Qualifier ions, } \\
\mathrm{m} / \mathrm{z}\end{array}$ \\
\hline \multicolumn{4}{|l|}{16 priority PAHs - external standard } \\
\hline NA & 5.2 & 128 & 127 \\
\hline $\mathrm{ACN}$ & 6.7 & 152 & 151 \\
\hline $\mathrm{AC}$ & 6.9 & 153 & 154 \\
\hline FL & 7.4 & 166 & 165 \\
\hline PHE & 8.35 & 178 & 176 \\
\hline AN & 8.38 & 178 & 176 \\
\hline FA & 9.5 & 202 & 200 \\
\hline PY & 9.7 & 202 & 200 \\
\hline $\mathrm{B}[\mathrm{a}] \mathrm{A}$ & 10.95 & 228 & 226 \\
\hline $\mathrm{CHR}$ & 10.99 & 228 & 226 \\
\hline $\mathrm{B}[\mathrm{b}] \mathrm{F}$ & 12.0 & 252 & 250 \\
\hline $\mathrm{B}[\mathrm{k}] \mathrm{F}$ & 12.0 & 252 & 250 \\
\hline $\mathrm{B}[\mathrm{a}] \mathrm{P}$ & 12.3 & 252 & 250 \\
\hline IP & 13.6 & 276 & 274 \\
\hline $\mathrm{D}[\mathrm{a}, \mathrm{h}] \mathrm{A}$ & 13.6 & 278 & 276 \\
\hline $\mathrm{B}[\mathrm{g}, \mathrm{h}, \mathrm{i}] \mathrm{P}$ & 13.9 & 276 & 274 \\
\hline \multicolumn{4}{|l|}{ F-PAHs - internal standard } \\
\hline 5-fluoroacenaphthylene (F-ACN) & 6.6 & 169.9 & 168.9 \\
\hline 1-fluoropyrene (F-PY) & 7.1 & 167 & 182 \\
\hline 9-fluorobenzo[k]fluoranthene $(\mathrm{F}-\mathrm{B}[\mathrm{k}] \mathrm{F})$ & 9.6 & 220.0 & 109.9 \\
\hline
\end{tabular}

The chromatograms of the certified PAH mix demonstrated that two compounds, F-PAHs, i.e. F-B $[\mathrm{k}] \mathrm{F}$ and F-ACN, fitted well as internal standard for the certified analyte tested. The chromatographic data for the FPY varied among identical measurements, therefore, F-PY could not be used as internal standard for determination of PAHs in the described conditions. Additionally, Nagy et al. [25] mentioned another problem of using F-PAHs as surrogate standards in the analysis for PAHs in surface water and sediment samples when the internal standard was added to the system before the separation phase. They found that F-PY could not be extracted from sediment samples, but can be successfully used for water samples [25]. For the additional testing of the method, the water extracts of oil shale ash were analyzed for PAHs. In these samples the presence of miscellaneous traces as other combustion related compounds greatly affected the intensity of F-ACN peaks and was not equal for all samples. Therefore, in our case only one internal standard F-B $[\mathrm{k}] \mathrm{F}$ could be used for quantification of PAH contents in oil shale solid wastes. Nevertheless, the results obtained by using only one 
F-PAH as internal standard are quite satisfactory. Consequently, the analytical method described in the present study is a rapid and simple procedure that allows reliable determination of PAHs. This method, based on the technique using F-PAHs as internal standards and GC-MS as the analytical technique, was validated by means of certified reference samples.

\section{Conclusions}

1. The first step in the analytical determination of priority pollutants, PAHs, in environmental matrices includes separation (extraction) of the fraction concerned. It was found that extracting PAHs from oil shale fly ash by water steam distillation into hexane gives somewhat better results than Soxhlet and ultrasonic extractions, while Soxhlet is more effective than ultrasonic extraction, especially for heavy PAHs.

2. The use of recently introduced monofluorinated PAHs (F-PAHs ${ }^{\circledR}$ ) as internal standards could improve precision of the quantification. However, from the reagents tested only one internal standard, $\mathrm{F}-\mathrm{B}[\mathrm{k}] \mathrm{F}$, could be used for quantification of PAHs content in oil shale solid wastes. Testing F-ACN and F-PY as internal standards did not give reliable results. The results obtained by using this F-PAH are quite satisfactory.

\section{Acknowledgements}

Financial support from the project EST-02/003 according to bilateral cooperation in science and technology (WTZ) between Federal Ministry of Education and Research, Germany and Ministry of Education and Research, Estonia, and Estonian Science Foundation (grant No. 6828) is gratefully acknowledged. The authors wish to thank Prof. A. Kettrup and Dr. I. Gebefügi for the fruitful discussions, and Mrs. P. Laas for technical assistance.

\section{REFERENCES}

1. US Environmental Protection Agency Method 610 - polynuclear aromatic hydrocarbons; appendix A: methods for organic chemical analysis of municipal and industrial wastewater; CWA methods approved for use at 40 CFR 136. http://www.epa.gov/waterscience/methods/method/organics/610.pdf.

2. Nollet, L. M. L. Chromatographic Analysis of the Environment. Series: Chromatographic science series Vol. 93. Boca Raton. 2006. 3rd ed. 1320 pp.

3. ISPAC 2003 International Society for Polycyclic Aromatic Compounds 2003. PAH structure/properties http://www.ispac.org/Links.htm. 
4. Eurachem / EUROLAB / CITAC / Nordtest / AMC Guide: Measurement uncertainty arising from sampling: a guide to methods and approaches / Ramsey, M., Ellison, S. (eds.). Eurachem, 2007. http://www.eurachem.org/ guides/UfS_2007.pdf.

5. Ramsey, M., Thompson, M., Hale, M. Objective evaluation of precision requirements for geochemical analysis using robust analysis of variance // J. Geochem. Explor. 1992 Vol. 44, No. 1-3. P. 23-26.

6. Wang, W., Meng, B., Lu, X., Liu, Y., Tao, S. Extraction of polycyclic aromatic hydrocarbons and organochlorine pesticides from soils: A comparison between Soxhlet extraction, microwave-assisted extraction and accelerated solvent extraction techniques // Analyt. Chim. Acta. 2007. Vol. 602, No. 2. P. 211-222.

7. Stephens, D. L., McFadden, T., Heath, D. O., Mauldin, R. F. The effect of sonication on the recovery of polycyclic aromatic hydrocarbons from coal stack ash surfaces // Chemosphere. 1994. Vol. 28, No. 10. P. 1741-1747.

8. Shu, Y. Y., Lao, R. C., Chiu, C. H., Turle, R. Analysis of polycyclic aromatic hydrocarbons in sediment reference materials by microwave-assisted extraction // Chemosphere. 2000. Vol. 41, No. 11. P. 1709-1716.

9. Shimmo, M., Adler, H., Hyotylainen, T., Hartonen, K., Kulmala, M., Riekkola, M.-L. Analysis of particulate polycyclic aromatic hydrocarbons by on-line coupled supercritical fluid extraction-liquid chromatography-gas chromatography-mass spectrometry // Atmos. Environ. 2002. Vol. 36, No. 18. P. 29852995.

10. Zougagh, M., Rios, A., Valcárcel, M. Direct automatic screening and individual determination of polycyclic aromatic hydrocarbons using supercritical fluid extraction coupled on-line with liquid chromatography and fluorimetric detection // Anal. Chim. Acta. 2004. Vol. 524, No. 1-2. P. 279-285.

11. Höhne, J., Eschenbach, A., Niemeyer, B. Removal of contaminants with high boiling points from soil and sludge by a steam distillation treatment // International Scientific Colloquium Modelling for Saving Resources, Riga, May 17-18, 2001. http://www.modlab.lv/publications/msr2001/pdf/113-116.pdf.

12. Teinemaa, E. The Environmental Fate of the Particulate Matter and Organic Pollutants from an Oil Shale Power Plant. PhD thesis. Department of Chemistry, University of Tartu, Estonia. Tartu, 2003.

13. Poster, D., Schantz, M., Sander, L., Wise, S. Analysis of polycyclic aromatic hydrocarbons (PAHs) in environmental samples: a critical review of gas chromatographic (GC) methods // Anal. Bioanal. Chem. 2006. Vol. 386, No 4. P. 859-881.

14. Hyötyläinen, T. On-line coupling of extraction with gas chromatography // J. Chromatogr. A. 2008. Vol. 1186, No. 1-2. P. 39-50.

15. Cam, D., Gagni, S., Lombardi, N., Punin, M. O. Solid-phase microextraction and gas chromatography-mass spectrometry for the determination of polycyclic aromatic hydrocarbons in environmental solid matrices // J. Chromatogr. Sci. 2004. Vol. 42, No. 6. P. 329-339.

16. Itoh, N., Numata, M., Aovagi, Y., Yarita, T. Comparison of low-level polycyclic aromatic hydrocarbons in sediment revealed by Soxhlet extraction, microwaveassisted extraction, and pressurized liquid extraction // Anal. Chim. Acta. 2008. Vol. 612, No. 1. P. 44-52.

17. Sun, P., Weavers, L. K., Taerakul, P., Walker, H. W. Characterization of polycyclic aromatic hydrocarbons (PAHs) on lime spray dryer (LSD) ash using different extraction methods // Chemosphere. 2006. Vol. 62, No. 2. P. 265-274. 
18. Heiden, A., Hoffmann, A., Kolahgar, B. Comparison of the sensitivity of solid phase microextraction (SPME) and stir bar sorptive extraction (SBSE) for the determination of polycyclic aromatic hydrocarbons (PAHs) in water and soil samples. 2001. http://www.labplus.co.kr/tech/upload/an-2001-08_PAH.pdf.

19. Paalme, L., Voll, M., Urbas, E., Palvadre, R., Johannes, I., Kirso, U. Oil shale region influence on the atmospheric pollution of Lake Peipsi // Proc. Estonian Acad. Sci. Chem. 1990. Vol. 39, No. 1. P. 18-27 [in Estonian, abstract in English].

20. Kirso, U., Laja, M., Urb, G. Polycyclic aromatic hydrocarbons (PAH) in ash fractions of oil shale combustion: fluidized bed vers pulverized firing // Oil Shale. 2005. Vol. 22, No. 4S. P 537-545.

21. Determination of Environmental Hazard of Spent Shale. - Estonian Environmental Research Center. Report. Tallinn, 2003 [in Estonian]. (http://www.envir. ee/jaatmed/poolkoksi_uuring.pdf).

22. Havenga, W. J., Rohwer, E. R. Chemical characterization and screening of hydrocarbon pollution in industrial soils by headspace solid-phase microextraction // J. Chromatogr. A. 1999. Vol. 848, No. 1-2. P. 279-295.

23. Kirso, U., Karelson, G., Schmitt-Kopplin, P., Lintelmann, J., Gebefügi, I. Polycyclic aromatic compounds in oil shale wastes $/ / 21^{\text {th }}$ International Symposium on Polycyclic Aromatic Compounds (ISPAC), Aug. 5-10, 2007. Trondheim, Norway. P. 85.

24. Luthe, G., Ramos, L., Dallüge, J., Brinkman, U. A. Th. Monofluorinated analogues of polycyclic aromatic hydrocarbons as internal standards for GC-MS in environmental analysis // Chromatographia. 2003. Vol. 57, No. 5-6. P. 379383.

25. Nagy, P., Fekete, J., Sharma, V. Monofluorinated polycyclic aromatic hydrocarbons: Surrogate standards for HPLC analysis of surface water and sediment samples // J. Liq. Chromatogr. Relat. Technol. 2008. Vol. 31, No. 2. P 240-249.

Presented by V. Lahtvee

Received May 14, 2008 